\title{
Stem Cell Factor Is a Neurotrophic Factor for Neural Crest-Derived Chick Sensory Neurons
}

\author{
Josette F. Carnahan, Darshna R. Patel, and James A. Miller \\ Amgen Center, Neurobiology Department, Thousand Oaks, California 91320
}

\begin{abstract}
We have found that stem cell factor (SCF) selectively enhances the survival of cultured embryonic chick dorsal root ganglia (DRG) neurons. Neurons grown in the presence of SCF expressed both neurofilament $150 \mathrm{kDa}$ subunit and calcitonin-gene related peptide. SCF does not, however, enhance the survival of parasympathetic, placode-derived sensory or sympathetic neurons in culture. Combining SCF with brain-derived neurotrophic factor or neurotrophin-3, but not with NGF, maintains more neurons than either factor alone, suggesting that these factors have partially overlapping activities. SCF preferentially rescues small neurons from the DRG. Labeling studies with bromodeoxyuridine indicate that the neurons sustained by SCF are not differentiating from a dividing progenitor.
\end{abstract}

[Key words: stem cell factor, sensory neurons, neurotrophic factor, development, differentiation, chick, hematopoiesis]

Autonomic neurons and melanocytes are derived from a transient embryonic structure, the neural crest (Le Douarin, 1982). The phenotypic diversity generated by crest progenitors arises along and at the end of various migratory pathways. For example, trunk crest cells migrating under the ectoderm differentiate into melanocytes, while those undergoing ventral migration between the neural tube and somites populate the dorsal root ganglion (DRG), the sympathetic ganglia, and the adrenal primordium. Even after crest cells have migrated and coalesced into spinal ganglia, both pigment cells and neurons can be generated from undifferentiated precursors still present in the forming ganglia (Duff et al., 1991). In fact, both in vivo lineage tracing experiments (Le Lievre et al., 1980; Bronner-Fraser and Fraser, 1989; Frank and Sanes, 1991) and clonal analysis in vitro (Sieber-Blum and Cohen, 1980; Baroffio et al., 1988) have demonstrated the existence of pluripotent progenitors both in the neural crest and in the migrating crest populations. In the chick embryo, by day 4 of gestation (E4), trunkal crest cells have reached both dorsal root sensory and sympathetic ganglia (Weston, 1963). Between E4 and E7, chick DRG contain progenitors whose initial survival is independent of NGF (Ernsberger and Rohrer, 1988). As development proceeds, sensory neuron sur-

\footnotetext{
Received Jan. 8, 1993; revised Aug. 30, 1993; accepted Sept. 2, 1993.

We thank Drs. Alun Davies, Paul H. Patterson, and Kristina Zsebo for their helpful suggestions. We also thank Drs. Frank Martin and Keith Langley, and Mrs. Beth Mendiaz for providing the recombinant chicken SCF.

Correspondence should be addressed to Dr. Josette F. Carnahan, Amgen Center, Neurobiology Department, B5, 1900 Oak Terrace Lane, Thousand Oaks, CA 91320.

Copyright (C) 1994 Society for Neuroscience $0270-6474 / 94 / 141433-08 \$ 05.00 / 0$
}

vival can be enhanced by NGF, brain-derived neurotrophic factor (BDNF), and neurotrophin-3 (NT3) (Levi-Montalcini and Angeletti, 1968; Barde et al., 1980; Lindsay et al., 1985; Rohrer et al., 1985; Ernfors et al., 1990; Hohn et al., 1990; Maisonpierre et al., 1990).

Stem cell factor (SCF) was recently purified from a rat liver cell line-conditioned medium (Zsebo et al., 1990). Under different names, the same factor was characterized from other sources (Huang et al., 1990; Williams et al., 1990). SCF is the ligand for the receptor (c-kit) encoded by the proto-oncogene W (Huang et al., 1990). Mouse mutants lacking functional SCF (S1) and c-kit (W) share very similar phenotypic defects in three cell lineages (Mayer and Green, 1968; Witte, 1990): germ cell, hematopoiesis, and melanogenesis (Besmer, 1991). Both c-kit and SCF are expressed in the nervous system (Matsui et al., 1990; Orr-Urtreger et al., 1990; Keshet et al., 1991; Motro et al., 1991; Morii et al., 1992), raising the possibility that SCF may also act on neurons. Chicken SCF was recently cloned from a chicken brain cDNA library and shown to have 57\% homology at the amino acid level with human SCF (F. Martin, personal communication). Here we demonstrate a neurotrophic activity for chicken SCF on chicken DRG neurons in vitro.

\section{Materials and Methods}

Cell culture. Ganglia were dissected from White Leghorn chick embryos at various ages, cleaned from surrounding tissue, trypsinized, and dissociated as described (Barde et al., 1980); two sequential preplating steps were used to enrich for neuronal cells. Cells were then plated at 1000 2000 cells (high density) or 100-200 cells (low density) per well on eightwell tissue culture chamber slides (Nunc, Inc., Naperville, IL) coated with polyornithine/laminin (Sigma, St. Louis, MO) (Lindsay et al., 1985). Cultures were maintained in F-14 medium (Barde et al., 1980), supplemented with $10 \%$ heat-inactivated horse serum (GIBCO, Grand Island, NY). The factors used were mouse 2.5S NGF (Boehringer Mannheim, Indianapolis, IN) used at $10 \mathrm{ng} / \mathrm{ml}$, and human brain-derived neurotrophic factor (BDNF), human NT3, and chicken SCF used at $10-20 \mathrm{ng} / \mathrm{ml}$, which were recombinant proteins generously provided by Bob Rosenfeld (BDNF), Dr. Jane Talvenheimo and Ling Cai (NT3), and Dr. Keith Langley and Beth Mendiaz (SCF) (Amgen Center, CA)

Quantitation of neuronal survival. Quantitation of neuronal survival was based on morphological observations using light microscopy. Neurons were counted under $250 \times$ magnification, once at $4 \mathrm{hr}$ postplating (where neurons were defined as phase bright with round cell bodies, with short or no neurite) and again at $48 \mathrm{hr}$ postplating. Only phasebright cells with neurites at least four times larger than the cell diameter were scored as surviving neurons. The percentage of survival is calculated as the ratio of these two counts for each individual well. Each experimental condition had four identical wells, and each experiment was repeated three to five times.

Image analysis of neuronal size distribution. Neurons were plated as described and photographed live at $48 \mathrm{hr}$ postplating using light microscopy with a $25 \times$ phase-contrast objective. We determined neuronal perimeter from the photograph using an image analyzer (Cambridge 


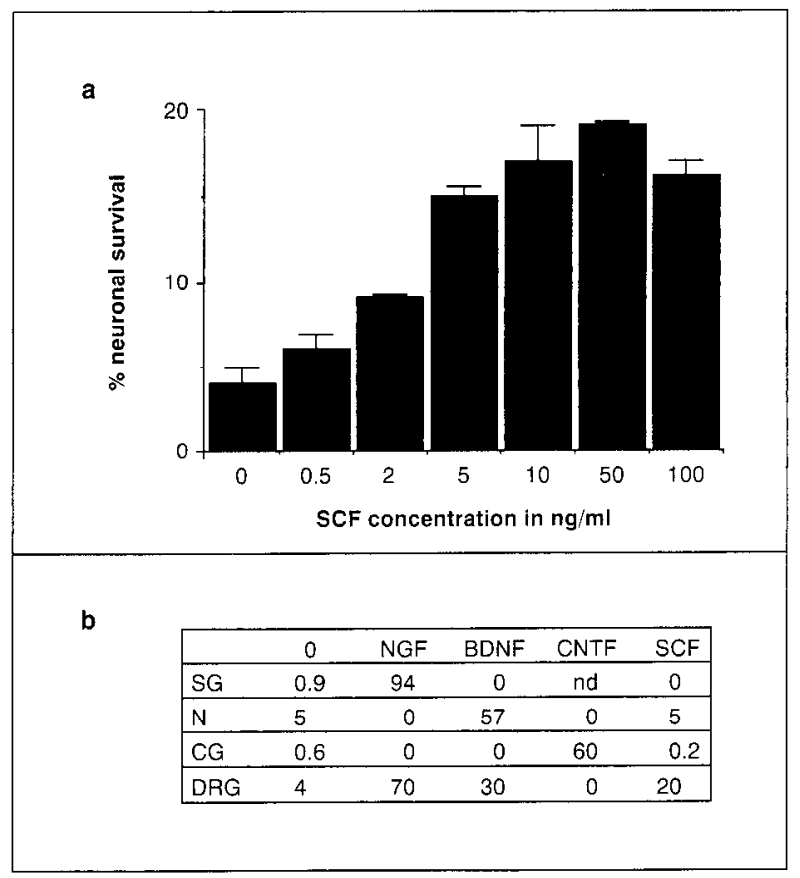

Figure 1. SCF rescues in a dose-dependent manner $(a)$ and specifically neural crest-derived sensory neurons $(b)$. $a$, E8 DRG neurons were grown for $48 \mathrm{hr}$ and their survival was determined for concentrations of SCF ranging from $0.5 \mathrm{ng} / \mathrm{ml}$ to $100 \mathrm{ng} / \mathrm{ml}$, compared with survival without any added growth factor. $b$, Neurons from selected peripheral ganglia $(S G$, sympathetic ganglia; $C G$, parasympathetic ciliary ganglia; $N$, placode-derived sensory neurons from nodose ganglia; and neural crest-derived sensory neurons from DRG) were plated onto polyornithine/laminin-coated multichamber slides at a final density of $50-100$ neurons per well. Sampled wells were scored $5 \mathrm{hr}$ postplating for attached neuron-like cells (round, phase bright, often already neurite bearing) and after $48 \mathrm{hr}$ neurite-bearing cells (neurite longer than 3 soma diameters) were scored again in each well. Neuronal survival is expressed in percentages, as the ratio of count 2 to count 1 , using murine NGF $(10 \mathrm{ng} / \mathrm{ml})$, recombinant human BDNF $(20 \mathrm{ng} / \mathrm{ml})$, ciliary neurotrophic factor $(C N T F)$ prepared from chick embryo eye extract used at a concentration subsaturating for survival of ciliary neurons dissociated culture, recombinant chick stem cell factor $(S C F ; 10 \mathrm{ng} / \mathrm{ml})$, or no growth factor $(0)$. These results were obtained using E8 chick embryos but the same qualitative specificity was obscrved at E6 and E12. For cach ganglion and developmental stage the experiment was repeated using 50 $\mathrm{ng} / \mathrm{ml}$ of purified growth factors with the same qualitative results.

Instruments, Cambridge, UK) equipped with an Epson LX 810 computer.

Immunofluorescent staining of cultures. Cultures were briefly rinsed with phosphate-buffered saline solution (PBS) (GIBCO, Grand Island, NY). Cells were fixed for 10 min on ice using freshly prepared $4 \%$ paraformaldehyde, and incubated in a blocking solution of $10 \%$ normal goat serum (NGS) (GIBCO, Grand Island, NY) in PBS containing 0.1\% Tween 20 for $30 \mathrm{~min}$. Primary antibody incubation was performed at room temperature (RT) for $1 \mathrm{hr}$ followed by four washes in PBS with $1 \%$ NGS. The blocking step was then repeated beforc incubation in secondary antibody (high fluorescein-conjugated, goat anti-mouse IgG; Antibodies Inc., Davis, CA). For double staining, high fluorescein goat anti-mouse was used to detect the monoclonal antibody and a biotinylated goat anti-rabbit antibody was used to detect the rabbit polyclonal antiserum; these were incubated simultaneously for $1 \mathrm{hr}$ at RT. After washing as described above, the cells were rinsed twice with PBS without serum and incubated with streptavidin-Texas red (Amersham, Arlington Heights, IL), diluted 1:200 for $30 \mathrm{~min}$ at RT. After final washings, the wells were carefully detached from the multichamber slides and the slides mounted using a glycerol solution containing phenylenediamine (Sigma, St Louis, MO) to prevent fading (Johnson and de Nogueira Araujo, 1981).

The sections were examined using a Zeiss Axioskop fluorescence mi- croscope equipped with a prism allowing the filters for fluorescein isothiocyanate (FITC) and rhodamine to be used simultaneously.

The antibodies used were rabbit antisera: against tyrosine hydroxylase (TH), 1:200 (Eugene Inc., Ramsey, NJ); calcitonin gene-related peptide (CGRP), 1:100 (Amersham); neurofilament $150 \mathrm{kDa}, 1: 200$ (Cambridge Research Biochemicals, Wilmington, DE).

BrdU incorporation. DRG from E5.5 chick embryos were dissociated as described above and preplated in $60 \mathrm{~mm}$ tissue culture petri dishes (Falcon, Lincoln Park, NJ). Simultaneously cells were incubated with $10 \mathrm{~nm}(+5)$-bromo-2'-deoxyuridine (BrdU) (Aldrich Chemicals, Milwaukee, WI) prepared fresh, added to the culture medium (Gratzner, 1982). $\Lambda$ fter $3 \mathrm{hr}$ cells were flushed with a pipette and collected for plating in medium containing both each neurotrophic factor and $\mathrm{BrdU}$; $48 \mathrm{hr}$ later cells were immunostained with an anti-BrdU monoclonal antibody at 1:500 (Caltag Laboratories, San Francisco, CA) and an antiserum against the $150 \mathrm{kDA}$ neurofilament subunit (Cambridge Research Biochemicals, Wilmington, DE).

\section{Results}

SCF is neurotrophic factor for neural crest-derived sensory neurons in vitro

We dissociated E8 chick DRG, preplated the cells twice to enrich for neurons, and cultured at a density of 1 neuron per $\mathrm{mm}^{2}$. We observed that recombinant chick SCF is a neurotrophic factor in the absence of any other added factor, and determined the dose-response of this effect. Survival activity plateaus at $10 \mathrm{ng}$ $\mathrm{ml}$ (Fig. 1a). This concentration was subsequently used for the rest of studies. Quantitation of neurotrophic activity was performed at low plating density to eliminate potential indirect effects due to the induction of a second factor secreted by the neurons themselves or by contaminating non-neuronal cells. In the initial experiments, SCF was added after neurons had attached, in order to eliminate the possibility that the observed SCF activity might be due to an effect on cell adhesion to the surface. However, we found that the percentage survival observed in the presence of SCF did not change when neurons were plated directly in medium containing the factor, indicating that the neurotrophic activity of SCF is not due to increased adhesion of selected neurons.

SCF was then tested for the ability to maintain survival of neurons from selected peripheral ganglia for at least $48 \mathrm{hr}$ of culture using known neurotrophic factors for each neuronal type as standards of comparison (Fig. $1 b$ ). We found that in the absence of any other growth factor, SCF promotes the survival of DRG sensory neurons but is ineffective in supporting neurons from nodose, sympathetic, or ciliary ganglia. Although survival was quantified after $48 \mathrm{hr}$, we found that SCF can maintain sensory neurons for at least 2 weeks in culture (data not shown). The response of these various ganglia to SCF was unchanged over the developmental period E6-E12. The results described above were obtained in medium containing serum; SCF has qualitative (Fig. 2C) and quantitative similar effects in serumfree medium.

\section{Neurons surviving in the presence of SCF are sensory neurons}

Progenitors able to differentiate into sympathetic as well as sensory neurons are present in avian DRG up to midgestation (Rohrer et al., 1985; Xue et al., 1985, 1987). The neurons supported by SCF are not differentiating along the sympathetic pathway based on our observations that they express neurofilaments and CGRP, lack immunoreactivity for TH (Fig. $2 A, B, D$ ), and are frequently observed to have a $\mathrm{T}$-shaped morphology. These characteristics are common to sensory ganglionic neurons in vivo as well as in culture in the presence of NGF or BDNF. However, not all sensory neurons are SCF responsive at E8; 

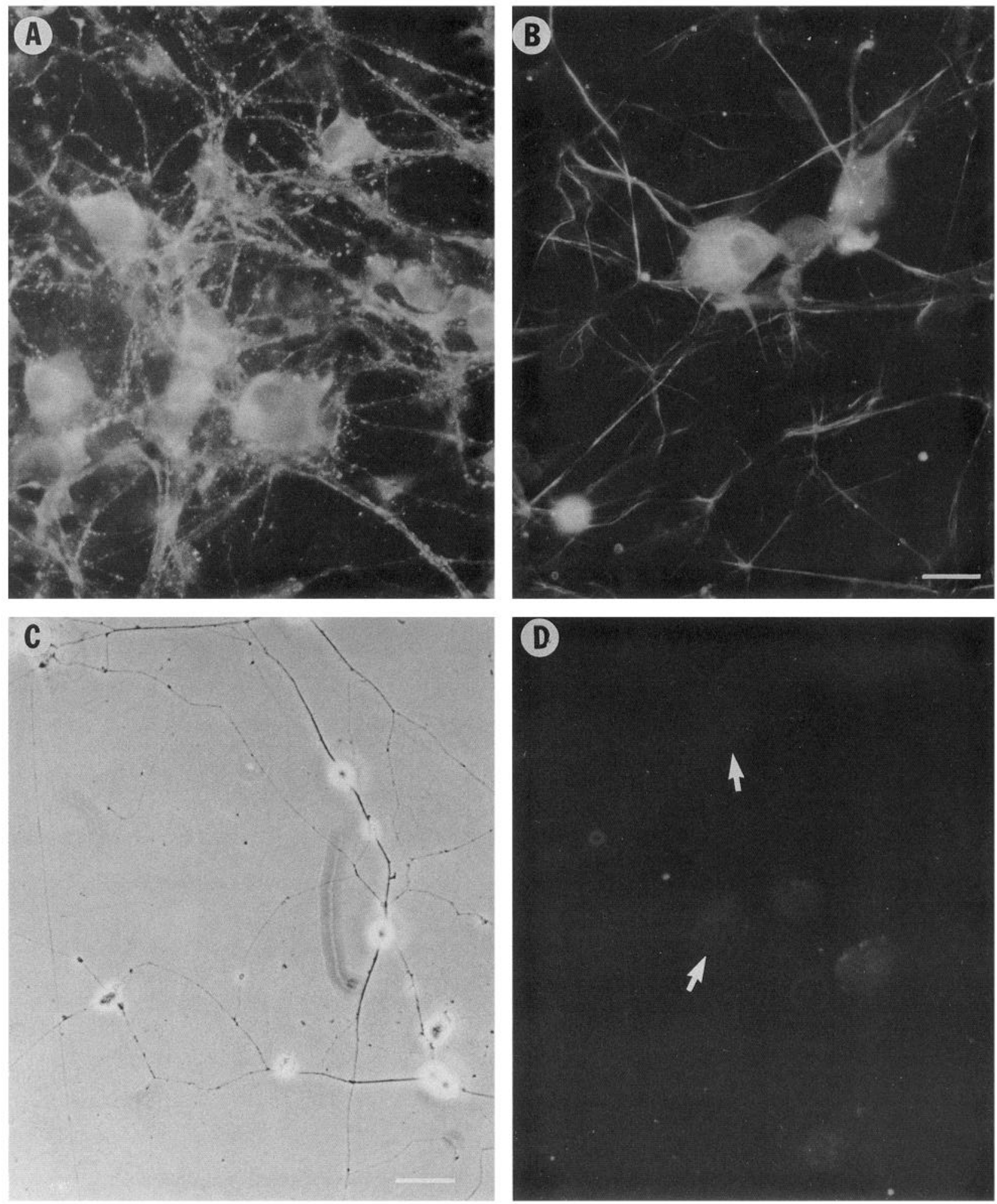

Figure 2. Neurons grown in SCF are sensory neurons. E8 DRG were plated at high density and after $4 \mathrm{~d}$ in culture immunostained using polyclonal antisera against CGRP $(A)$, neurofilament $150 \mathrm{kDa}$ subunit $(B)$, and TH $(D)$ as described. $C$ shows a picture of live neurons in phase contrast in a sister culture grown in serum-free medium containing SCF. In $D$, the arrows indicate two examples of neurons grown in the presence of SCF, lacking TH immunostaining. Scale bar: $22 \mu \mathrm{m}$ for $A, B$, and $D ; 72 \mu \mathrm{m}$ for $C$.

typically $20 \%$ of the total number of neurons plated are supported by SCF (Fig. 1a). The percentage of neurons that survive in SCF does not change when DRG from various rostrocaudal levels are cultured (data not shown), suggesting either that there is no correlation between SCF dependence and target innervation, or that all surviving neurons have a common target, such as the skin. We also observed that the neuropeptide immunoreactivities for substance $\mathrm{P}$, CGRP (Fig. $2 A$ ), and somatostatin 


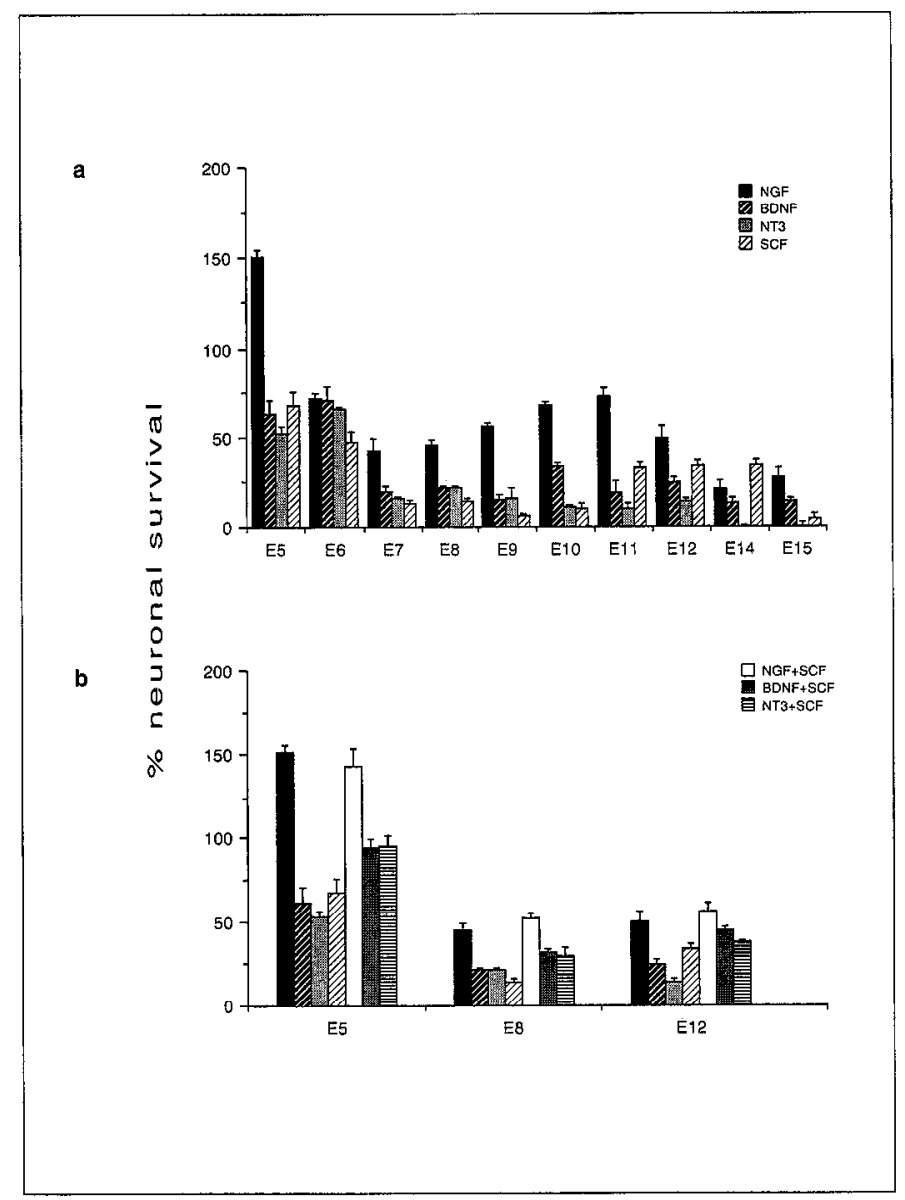

Figure 3. SCF neurotrophic activity is developmentally regulated and overlaps totally with NGF but not with BDNF or NT3. $a$, Survival at low-density plating was determined after $48 \mathrm{hr}$ in presence of SCF and compared with individual neurotrophic factors at various stages of development. $b$, Survival in presence of individual neurotrophic factors was compared to survival in presence of combinations of two factors, at three developmental stages. In this figure the percentage survival in absence of any growth factor was subtracted for clarity but did not exceed $6 \%$ before E1 2 and was on the order of $14 \%$ thereafter.

showed comparable heterogeneity between sister cultures grown in SCF, NGF, BDNF, or NT3, consistent with the known heterogeneity of spinal ganglia.

\section{SCF responsiveness is developmentally regulated}

Neuronal survival in culture using individual neurotrophic factors. The developmental time course of SCF responsiveness was determined in parallel with that of NGF, BDNF, and NT3 (Fig. $3 a$ ). For clarity, the background percentage survival in control cultures, which lack added growth factors, has been subtracted at each time point shown in this figure; up to E12 the growth factor-independent survival was less than $6 \%$, rising by E1 5 to $14 \%$. We observed a similar, biphasic course of responsiveness for NGF, BDNF, and SCF. NT3 survival activity did not demonstrate a pronounced biphasic nature, and its ability to maintain survival ceased between E12 and E14. At the low plating densities used in these experiments (100 neurons per well), the percentage of neurons surviving with BDNF was much lower than previously reported (Lindsay et al., 1985). We therefore repeated the experiment using high-density plating (2000 neurons per well), conditions more comparable to earlier reports.
Survival under these conditions was considerably higher, comparable to the prior reports. This may indicate an autocrine or paracrine effect, with the neurons or auxiliary cells secreting factors supporting their own survival in vitro.

Survival effect of SCF in combination with other neurotrophins. Since SCF did not maintain all DRG neurons in culture, we examined the survival effects of adding SCF in combination with either NGF, BDNF, or NT3 (Fig. 3b), all factors being used at saturating concentration. We found no increase survival percentages when SCF was combined to NGF, implying that the neurons supported by SCF are a subpopulation of the total number of NGF-responsive neurons. However, combination of SCF with either BDNF or NT3 produced higher survival levels when compared to either factor alone. Therefore, some of the DRG neurons can respond to SCF, BDNF, or NT3.

\section{$S C F, N G F$, and BDNF rescue different neuronal populations}

Sensory neurons grown in culture exhibit the same size heterogeneity observed in vivo (Fig. 4). We noticed that neurons surviving in the presence of SCF tended to be smaller than those grown with NGF; this observation was quantified using optical microscopy and image analysis. Figure 4 presents the results of such an analysis of E7 cells (these data are comparable to those obtained at E12, not shown). Neurons grown in the presence of SCF tend to have smaller cell bodies, especially when compared with those grown in the presence of BDNF, supporting the notion that SCF rescues only a subpopulation of neurons.

\section{SCF acts on postmitotic neurorls}

SCF was initially characterized as a proliferation-inducing factor for murine bone marrow hematopoietic stem cells and a mast cell line (Huang et al., 1990; Nocka et al., 1990; Williams et al., 1990; Zsebo et al., 1990). Thus, SCF could be enhancing proliferation of neuronal progenitors in the DRG cultures. BrdU labeling reveals that neurons in the cultures treated with SCF are, in fact, postmitotic (Fig. 5a,b, arrows). This was also the case for the vast majority of neurons grown in NGF, BDNF, or NT3, although we did observe a small but significant number (estimated to be between $2 \%$ and $5 \%$ ) of neurons (neurite-bearing) double labeled for BrdU and neurofilaments in such cultures (Fig. $5 c$, in BDNF; $5 d$ in NGF). Interestingly, we also observed in the SCF cultures occasional cells that were flat and neurite free but expressed neurofilaments and were BrdU labeled (Fig. $5 a$, curved arrow). These cells, although rare in the SCF cultures, were not found during extensive observations of sister cultures that had been grown with NGF, BDNF, or NT3. In these expcriments, we examincd 4000-5000 ncurons per set of culture conditions and found these cells only in SCF cultures.

\section{Discussion}

SCF, a new neurotrophic factor

We report here our finding of a new component in the spectrum of activities known for SCF, namely, its ability to act as a neurotrophic factor, and we compare this activity with those of the well-established neurotrophins NGF, BDNF, and NT3. SCF is active at a saturating concentration comparable to that of other neurotrophins $(10 \mathrm{ng} / \mathrm{ml})$, with a half-maximum concentration of $2 \mathrm{ng} / \mathrm{ml}\left(4 \times 10^{-8} \mathrm{M}\right)$. In our survival assays, of the peripheral neurons tested, only DRG sensory neurons were responsive to SCF. This is in agreement with the reported expression of both SCF and its receptor c-kit in murine DRG (Orr-Urtreger et al., 1990; Keshet et al., 1991; Motro et al., 1991). In addition, the 


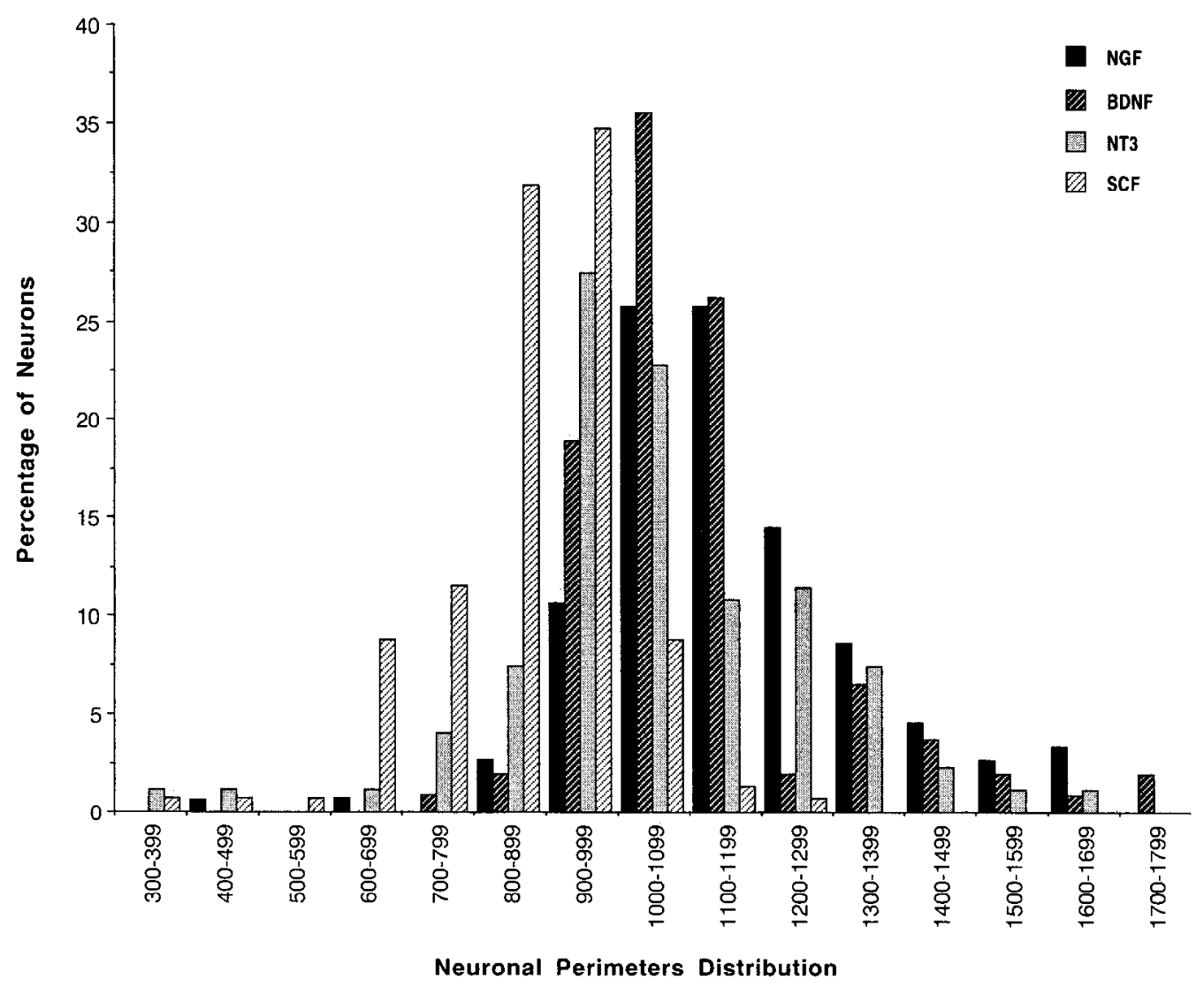

Figure 4. SCF preferentially rescues small neurons. We measured soma perimeters (in micrometers) of neurons dissected from E7 DRG embryos and grown for $24 \mathrm{hr}$ in the presence of individual ncurotrophic factors. For cach set of culturcs, betwcen 150 and 200 ncurons were measured and the numbers were arbitrarily divided into categories spanning $100 \mu \mathrm{m}$ each. Each bar represent the percentage of neurons that fall into each category. The solid bars represent the perimeter distribution of neurons grown with NGF, the dark hatched bars represent BDNF, the light hatched bars represent SCF, and the stippled bars represent NT3.

overlapping expression of SCF and its receptor in the DRG suggests that SCF may not be a classical, target-derived factor but rather a factor acting in a paracrine or autocrine fashion.

A subpopulation of neurons taken from E5-E15 DRG can be maintained in SCF alone. This broad age of responsiveness parallels closely that of NGF and BDNF (Fig. 2A). Neuronal responsiveness to SCF seems to show two maxima near E5 and E10, which are also similar to those found for NGF and BDNF (Lindsay et al., 1985). These maxima correspond to the peak times for the birth of large and small neurons, respectively (McMillan and Simpson, 1978).

Although our findings with NGF, BDNF, and NT3 agrec with previous reports, it was surprising that cultures treated with NGF at E5 had a $150 \%$ survival rate (Fig. $2 A$ ). It is possible that at this early stage, in spite of our efforts to enrich for neurons, the cultures contained contaminating progenitors that were not scored as neurons, but divided and differentiated during the $48 \mathrm{hr}$ culture period. Alternatively, cells that were scored as neurons in the initial counting might actually be dividing in culture; this would, however, be inconsistent with reports that, unlike sympathetic neurons, sensory neurons do not divide (Anderson and Axel, 1986; Rohrer and Thoenen, 1987). In the initial scoring, we defined as neurons cells whose cell body was rounded and phase bright with either short or no neurites. It is our experience that upon neurofilament staining, all such cells are immunoreactive for neurofilament (data not shown). In addition, a significant number of neurons grown from E5.5 DRG in the presence of NGF, BDNF, or NT3 did show BrdU incorporation, supporting the possibility that some sensory neurons are still mitotic at this stage of development.

Although we found survival with BDNF to be affected by neuronal density, SCF supported the same percentage of neurons regardless of the plating density. This suggests a direct action on the neurons rather than an induction of another factor. In addition, we tested survival of sensory DRG neurons in response to SCF in the presence of blocking antiserum to NGF or to BDNF. Neither antiserum had any effect on neuronal survival (data not shown). Therefore, the neurotrophic activity of SCF is unlikcly to be mediated by secretion of either NGF or BDNF.

\section{$S C F$ is acting on a subpopulation of sensory neurons}

In the age range we examined (E5.5-E15), chicken SCF supports fewer neurons than does NGF. The SCF-supported neurons were apparently a subpopulation of the NGF-responsive neurons. Our attempts to correlate this subpopulation with a particular neuropeptide phenotype or a location along the rostrocaudal axis were unsuccessful. However, we did observe that smaller neuronal size (Fig. 4) and frequently a bipolar shape (data not shown) were characteristic features of the neurons responding to SCF, especially when compared to neurons grown in BDNF or NT3. The small size of neurons cultured in the presence of SCF might reflect the specificity of SCF in rescuing small sensory neurons, which would be consistent with their expression of CGRP, and also with the hypothesis that the neu- 

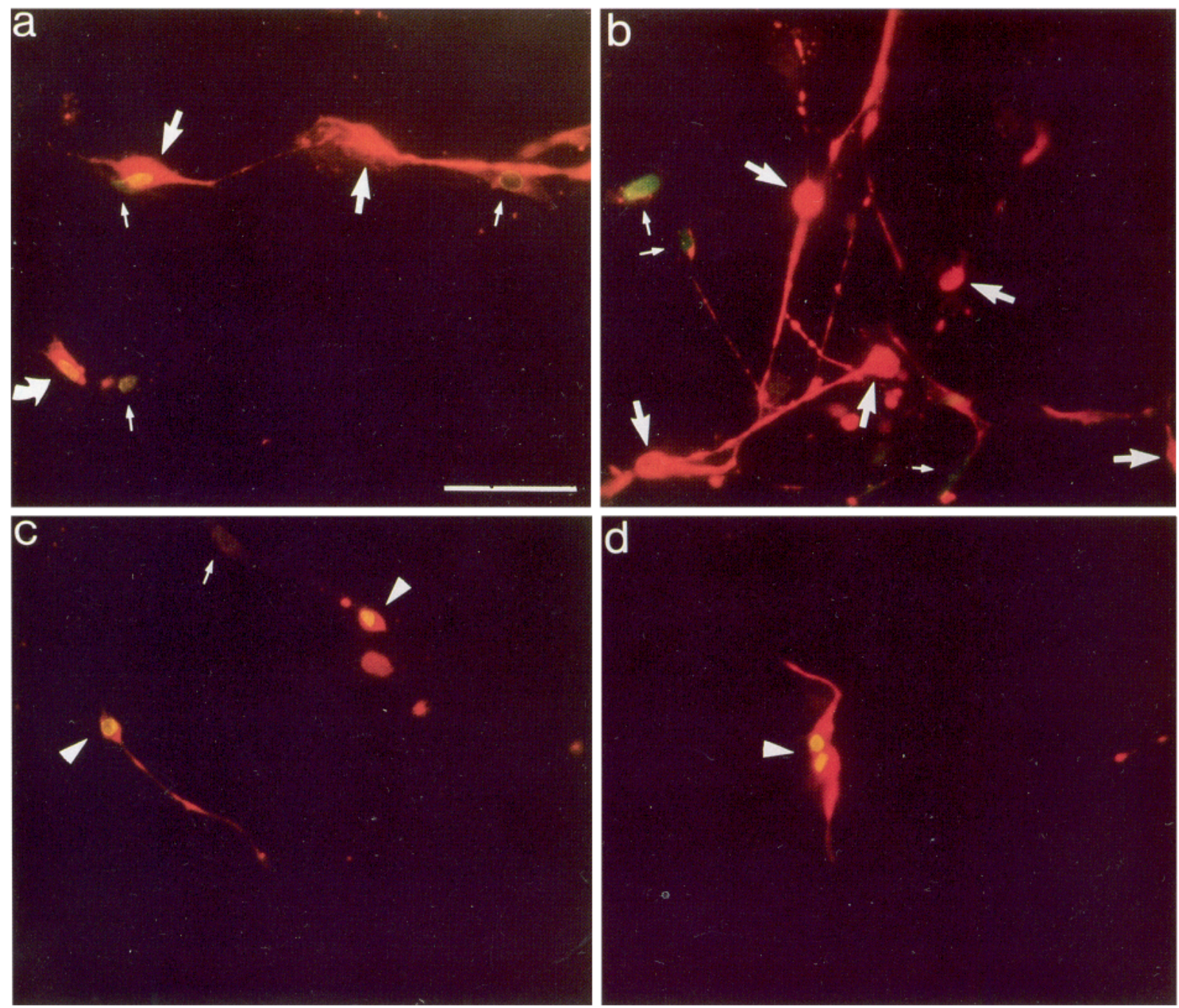

Figure 5. SCF is a trophic factor for postmitotic neurons. E5.5 DRG neurons were preincubated with BrdU prior to and during plating with various growth factors. They were then doubly immunostained for BrdU (green) and neurofilament (red). $a-d$ show representative fields of cultures grown in the presence of SCF $(a$ and $b), \operatorname{BDNF}(c)$, and $\operatorname{NGF}(d)$. The majority of neurons in all cultures were only labeled with neurofilament antibodies (thick arrows) and the BrdU incorporation was seen mainly in neurofilament-negative cells (thin arrows). $c$ and $d$ are selected fields from BDNF- and NGF-treated cultures, respectively, showing incorporation of BrdU in neurofilament-positive cells bearing neurites (arrowheads). Such cells could not be found in SCF treated cultures. In a the curved arrow points to the only type of cells that showed double staining for neurofilament and BrdU. These cells were typically small, flat, and without neurites. They were rare in the SCF cultured wells (less than $2 \%$ of the neurofilamentpositive cells) but were not at all found in NGF-, BDNF-, or NT3-treated cultures. Scale bar, $50 \mu \mathrm{m}$.

rons have skin as a target organ. Although the peak time for the birth of small sensory neurons is around E10 (McMillan and Simpson, 1978), small, CGRP-containing sensory neurons are present in the DRG as early as E5 (New and Mudge, 1986). It is possible these are the neurons responding to SCF in our cultures.

An alternative explanation is that neurons surviving in the presence of SCF might preferentially rescue younger neurons at all stages of development. Experiments are in progress to address these questions.

\section{$S C F$ rescues postmitotic neurons}

SCF has been reported to stimulate proliferation of hematopoietic progenitors (Berstein et al., 1991; de Vries et al., 1991), which prompted us to examine its effects at early stages of neuronal development. In contrast to previously reported activities on hematopoietic cells, SCF primarily rescued postmitotic neurons, as shown by the lack of incorporation of BrdU in neurite- bearing, neurofilament-stained cells (Fig. $5 a, b$ ). This is in contrast with the surprising finding of BrdU-labeled neurons in the cultures treated with BDNF, NGF, or NT3. Neurons cultured with BDNF, NGF, or NT3 were also found immunonegative for $\mathrm{TH}$, suggesting they are not from the pool of sympathetic progenitors. The BrdU labeling found in these latter cultures could be due to the presence of neurons that initially were growth factor independent and mitotic (Ernsberger and Rohrer, 1988), as discussed above. Although BDNF and NT3, but not NGF, have been reported to accelerate sensory neuronal maturation (Wright et al., 1992), we observed the same proportion of BrdUlabeled neurons in these three conditions. These labeled neurons may have initially been from the $5-6 \%$ of young neurons that are growth factor independent. However, the fact that we could not find labeled neurons in the cultures treated with SCF suggests that SCF might actually prevent neuronal maturation (neurite outgrowth and cell body growth). This hypothesis is reinforced by the presence in SCF cultures of small flat cells expressing 
both neurofilament and BrdU immunoreactivity but which are neurite free. These cells remain to be further characterized, but they could represent progenitors (sensory or sympathetic) arrested in their maturation. One could speculate that in vivo, SCF is maintaining a pool of progenitors present in the DRG.

\section{Significance of neurotrophic activity for SCF}

In addition to presumptive migrating melanoblasts, expression of c-kit has been reported both in ventrally migrating neural crest cells and in sensory neurons in mouse DRG at E15 (Keshet et al., 1991) and E12.5 (Manova and Bachvarova, 1991). In the mouse, mRNA for SCF is detectable in the DRG after E14 (B. Hogan, personal communication). The pattern of expression of SCF and its receptor in the mammalian nervous system is therefore consistent with the evidence of its neurotrophic activity on chicken neurons. We have preliminary evidence of a similar pattern of c-kit expression in avian tissues, including in the DRG, suggesting parallel roles for SCF in the two systems. Expression of c-kit seems restricted on sensory neurons (Keshet et al., 1991) but that of SCF spread over the entire ganglion. This suggests an autocrine/paracrine mechanism for SCF.

There is clear evidence that SCF is an early-acting factor in neural crest development in vivo. Injection of a blocking antibody to the SCF receptor into mouse embryos affects melanogenesis (Nishikawa et al., 1991). It will also be of interest to explore the relationship of SCF+BDNF, especially in the context of aggregation of neural crest cells to form DRG in vivo (Kalcheim et al., 1987). In addition, BDN $\Gamma$ has been shown to drive clonal neural crest cells toward neuronal differentiation (Sieber-Blum, 1991); thus, it might he of interest to investigate the effects of SCF upon the decision branch of neuronal or glial versus pigment lineage (Stocker et al., 1991).

So far we have not been able to demonstrate in vitro any neurotrophic activity for SCF in a mammalian species. Sequence analysis demonstrates that chicken SCF is quite divergent from any mammalian SCF studied to date (Martin, personal communication) with $57 \%$ homology in amino acid sequence. Though there is no cross-reactivity for ligand binding between the mammalian and avian nervous system, chicken SCF has actions consistent with those known for mammalian SCF when tested in a chicken hematopoietic assay (J. Lipsick, personal communication). Although no obvious sensory deficits have been reported for SCF or c-kit mutations, it is possible that deficits caused by these mutations are sufficiently subtle that they are as yet undetected. Given the relatively late appearance of SCF in developing mouse DRG, it is possible that in mammals SCF might not be an early neurotrophic factor but rather might be involved in a later step of neuronal maturation.

\section{References}

Anderson DJ, Axel R (1986) A bipotential neuroendocrine precursor whose choice of cell fate is determined by NGF and glucocorticoids. Ccll 47:1079-1090.

Barde Y-A, Edgar D, Thoenen HM (1980) Sensory neurons in culture: changing requirements for survival factors during embryonic development. Proc Natl Acad Sci USA 77:1199-1203.

Baroffio A, Dupin E, Le Douarin NM (1988) Clone-forming ability and differentiation potential of migratory neural crest cells. Proc Natl Acad Sci USA 85:5325-5329.

Berstein ID, Andrews RG, Zsebo KM (1991) Recombinant human stem cell factor enhances the formation of colonies by $\mathrm{CD} 34^{+}$and $\mathrm{CD} 34^{+} \mathrm{lin}^{-}$cells, and the generation of colony-forming cell progeny from CD34+lin- cells cultured with interleukin-3, granulocyte colo- ny-stimulating factor, or granulocyte-macrophage colony-stimulating factor. Blood 77:2316-2321.

Besmer P (1991) The kit ligand encoded at the murine Steel locus: a pleiotropic growth and differentiation factor. Curr Opin Cell Biol 3:939-946.

Bronner-Fraser M, Fraser S (1989) Developmental potential of avian trunk neural crest cells in situ. Neuron 3:755-766.

de Vries P, Brasel KA, Eisenman JR, Alpert AR, Williams DA (1991) The effect of recombinant mast cell growth factor on purified murine hematopoietic stem cells. J Exp Med 173:1205-1211.

Duff RS, Langtimm CJ, Richardson MK, Sieber-Blum M (1991) In vitro analysis of progenitor cell patterns in dorsal root ganglia of the quail embryo. Dev Biol 147:451-459.

Ernfors P, Wetmore C, Olson L, Persson H (1990) Identification of cells in rat brain and peripheral tissues expressing mRNA for members of the nerve growth factors family. Neuron 5:511-526.

Ernsberger U, Rohrer H (1988) Neuronal precursor cells in chick dorsal root ganglia: differentiation and survival in vitro. Dev Biol 126 $420-432$.

Frank E, Sanes JR (1991) Lineage of neurons and glia in chick dorsal root ganglia: analysis in vivo with a recombinant retrovirus. Development 111:895-908.

Gratzner HG (1982) A new reagent for detection of DNA replication. Science 218:474-475.

Hohn A, Leibrock J, Bailey K, Barde Y-A (1990) Identification and characterization of a novel member of the nerve growth/brain-derived neurotrophic factor family. Nature 344:339-341.

Huang E, Nocka K, Beier DR, Chu T-Y, Buck J, Lahm H-W, Wellner D, Leder P, Besmer P (1990) The hematopoietic growth factor KL is encoded by the $S l$ locus and is the ligand of the c-kit receptor, the gene product of the W locus. Cell 63:225-233.

Johnson G, de Nogueira Araujo G (1981) A simple method of reducing the fading of immunofluorescence during microscopy. J Immunol Methods 43:349-350.

Kalcheim C, Barde Y- $\Lambda$, Thoenen H, Le Douarin NM (1987) In vivo effect of brain-derived neurotrophic factor on the survival of developing dorsal root ganglion cells. EMBO J 6:2871-2873.

Keshel E, Lyman SD, Williams DE, Anderson DM, Jenkins NA, Copeland NG, Parada LF (1991) Embryonic RNA expression patterns of the $\mathrm{c}$-kit receptor and its cognate ligand suggest multiple functional roles in mouse development. EMBO J 10:2425-2435.

Le Douarin NM (1982) The neural crest. Cambridge: Cambridge UP.

Le Lievre CS, Schweizer GG, Ziller CM, Le Douarin NM (1980) Restrictions of developmental capabilities in neural crest cell derivatives as tested by in vivo transplantation experiments. Dev Biol 77:362378

Levi-Montalcini R, Angeletti PU (1968) Nerve growth factor. Physiol Rev 48:534-569.

Lindsay RM, Thoenen H, Barde Y-A (1985) Placode and neural crestderived sensory neurons are responsive at early developmental stages to brain-derived neurotrophic factor. Dev Biol 112:319-328.

Maisonpierre PC, Belluscio L, Squinto S, Ip NY, Furth ME, Lindsay RM, Yancopoulos GD (1990) Neurotrophin-3: a neurotrophic factor related to NGF and BDNF. Science 247:1446-1451.

Manova K, Bachvarova RF (1991) Expression of c-kit encoded at the $W$ locus of mice in developing embryonic germ cells and presumptive melanoblasts. Dev Biol 146:312-324.

Matsui Y, Zsebo KM, Hogan BLM (1990) Embryonic expression of a hematopoietic growth factor encoded by the $S /$ locus and the ligand for c-kit. Nature 347:667-669.

Mayer TC, Green MC (1968) An experimental analysis of the pigmented defect caused by mutations at the $W$ and the $S /$ loci in mice. Dev Biol 18:62-75.

McMillan V, Simpson SB (1978) Proliferative and degenerative events in the early development of chick dorsal root ganglia. 1. Normal development. J Comp Neurol 182:727-740.

Morii E, Hirota S, Kim H-M, Mikoshiba K, Nishimune Y, Kitamura $Y$, Nomura S (1992) Spatial expression of genes encoding c-kit receptors and their ligands in mouse cerebellum as revealed by in situ hybridization. Dev Brain Res 65:123-126.

Motro B, Van Der Kooy D, Rossant J, Reith A, Berstein A (1991) Contiguous patterns of c-kit and steel expression: analysis of mutations at the $W$ and $S /$ loci. Development 113:1207-1221.

New HV, Mudge AW (1986) Distribution and ontogeny of SP, CGRP, SOM and VIP in chick sensory and sympathetic ganglia. Dev Biol 116:337-346. 
Nishikawa S, Kusakabe M, Yoshinaga K, Ogawa M, Hayashi S-I, Kunisada T, Era T, Sakakura T, Nishikawa S-I (1991) In utero manipulation of coat color formation by a monoclonal anti-c-kit antibody. EMBO J 10:2111-2118.

Nocka K, Buck J, Levi E, Besmer P (1990) Candidate ligand for the c-kit transmembrane kinase receptor: $\mathrm{KL}$, a fibroblast derived growth factor stimulates mast cells and erythroid progenitors. EMBO J 9:32873294.

Orr-Urtreger A, Avivi A, Zimmer Y, Givol D, Yarden Y, Lonai P (1990) Developmental expression of c-kit, a proto-oncogene encoded by the W locus. Development 109:911-923.

Rohrer H, Thoenen H (1987) Relationship between differentiation and terminal mitosis: chick sensory and ciliary neurons differentiate after terminal mitosis of precursor cells, whereas sympathetic neurons continue to divide after differentiation. J Neurosci 7:3739-3748.

Rohrer H, Henke-Fahle S, El-Sharkawy T, Lux HD, Thoenen H (1985) Progenitor cells from embryonic chick dorsal root ganglia differentiate in vitro to neurons: biochemical and electrophysiological evidence. EMBO 4:1709-1714.

Sieber-Blum M (1991) Role of the neurotrophic factors BDNF and NGF in the commitment of pluripotent neural crest cells. Neuron 6:949-955.

Sieber-Blum M, Cohen AM (1980) Clonal analysis of quail crest cells: they are pluripotent and differentiate in vitro in absence of noncrest cells. Dev Biol 80:96-106.

Stocker KM, Sherman L, Rees S, Ciment G (1991) Basic FGF and
TGF-beta 1 influence commitment to melanogenesis in neural crestderived cells of avian embryos. Development 111:635-645.

Weston JA (1963) A radioautographic analysis of the migration and localization of trunk neural crest cells. Dev Biol 6:279-310.

Williams DE, Eisenman J, Baird A, Rauch C, Van Ness K, March CJ, Park LS, Martin U, Mochizuki DY, Boswell HS, Burgess GS, Cosman D, Lyman SD (1990) Identification of a ligand for the c-kit protooncogene. Cell 63:167-174.

Witte ON (1990) Steel locus defines new multipotent growth factor. Cell 63:5-6.

Wright EM, Vogel KS, Davies AM (1992) Neurotrophic factors promote the maturation of developing sensory neurons before they become dependent on these factors for survival. Neuron 9:139-150.

Xue ZG, Smith J, Le Douarin NM (1987) Developmental capacities of avian cmbryonic dorsal root ganglion cells: ncuropeptides and tyrosine hydroxylase in dissociated cell cultures. Dev Brain Res 34: 99-109.

Xue ZG, Smith J, Le Douarin NM (1985) Differentiation of catecholaminergic cells in cultures of embryonic avian sensory ganglia. Proc Natl Acad Sci USA 82:8800-8804.

Zsebo KM, Wypych J, McNiece IK, Lu HS, Smith KA, Karkare SB, Sachdev RK, Yuschenkoff VN, Birkett NC, Williams LR, Satyagal VN, Tung W, Bosselman RA, Mendiaz EA, Langley KE (1990) Identification, purification, and biological characterization of hematopoietic stem cell factor from Buffalo rat liver-conditioned medium. Cell 63:195-201. 